\title{
Malignant Gastric Ulcer: Carcinoma or Lymphoma?
}

\author{
Ji Hye Kim, Yong Hwan Kwon \\ Department of Internal Medicine, Kyungpook National University School of Medicine, Daegu, Korea
}

Question: A 38-year-old man visited emergency room with presenting a history of hematemesis. He had dyspepsia and hunger epigastric soreness for 6 months and lost $8 \mathrm{~kg}$ of body weight during 6 months. He underwent splenectomy due to splenic infarction before 20 years and has been treated for nephrotic syndrome for 10 years. On upper endoscopy, a $15 \mathrm{~mm}$-sized ulcerative lesion with whitish exudates was found at the posterior wall side of mid-body of the stomach (Fig. 1A) and irregular fold thickening with poor distension on air feeding was observed at the greater curvature of the upper body (Fig. 1B). Abdomen computerized tomography showed diffuse marked wall thickening of the stomach and multiple enlarged lymph nodes, retroperitoneal fat infiltrations and peritoneal carcinomatosis (Fig. 2).

What is the most likely diagnosis?

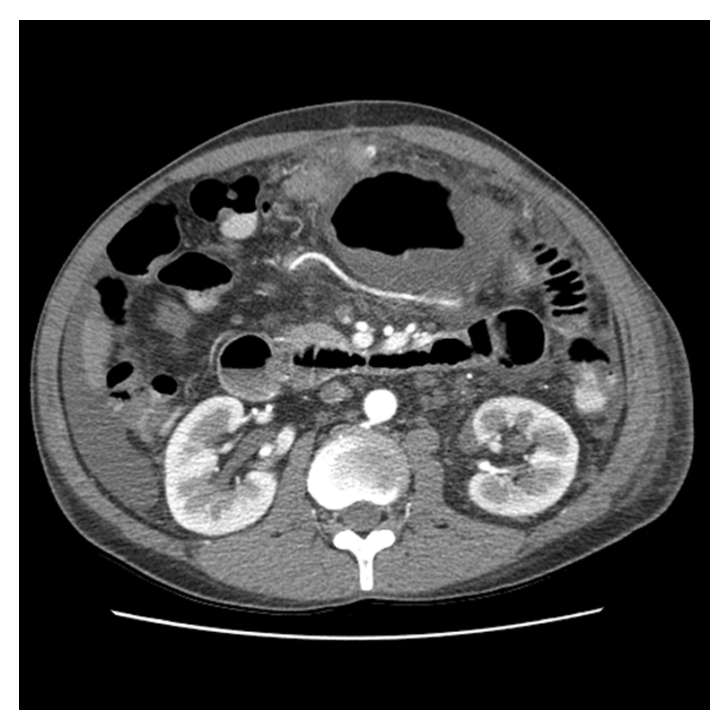

Fig. 2. Abdomen CT shows diffuse marked wall thickening of the stomach, multiple enlarged lymph nodes, retroperitoneal fat infiltrations and peritoneal carcinomatosis.
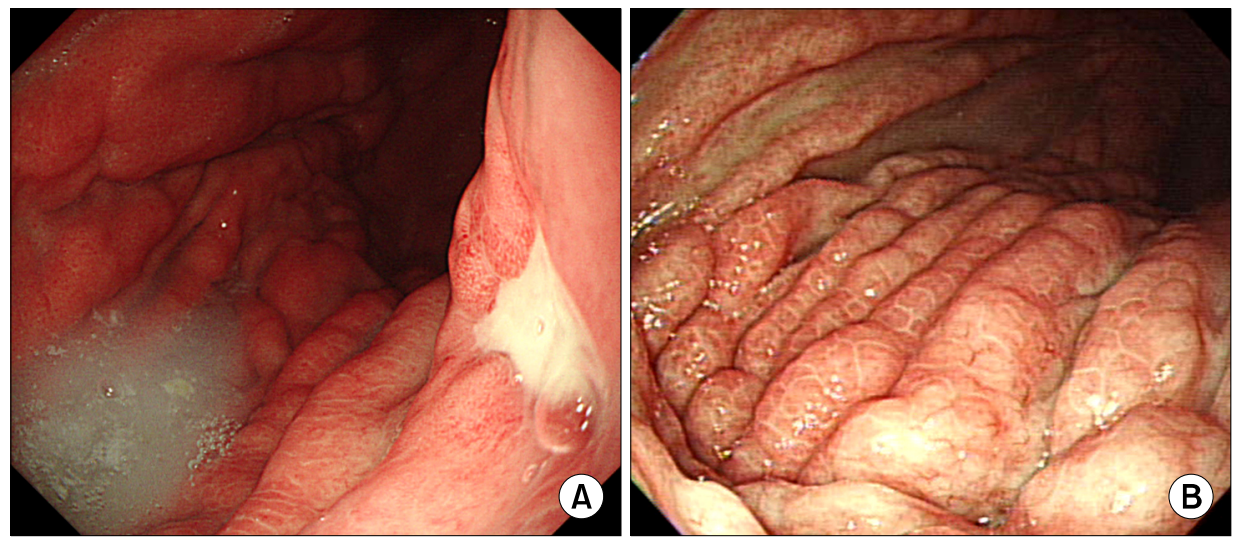

Fig. 1. (A) On upper endoscopy, a 15 mm-sized ulcerative lesion with whitish exudates is found at the posterior wall side of mid-body of the stomach. (B) Irregular fold thickening with poor distension on air feeding is observed at the greater curvature of the upper body.

Received: July 23, 2017 Revised: August 10, 2017 Accepted: August 10, 2017

Corresponding author: Yong Hwan Kwon

Gastric Cancer Center, Kyungpook National University Medical Center, 807 Hoguk-ro, Buk-gu, Daegu 41404, Korea

Tel: +82-53-200-2609, Fax: +82-53-200-2028, E-mail: tear9754006@yahoo.co.kr

Copyright $\odot 2017$ Korean College of Helicobacter and Upper Gastrointestinal Research

@ The Korean Journal of Helicobacter and Upper Gastrointestinal Research is an Open-Access Journal. All articles are distributed under the terms of the Creative Commons Attribution Non-Commercial License (http://creativecommons.org/licenses/by-nc/4.0) which permits unrestricted non-commercial use, distribution, and reproduction in any medium, provided the original work is properly cited. 

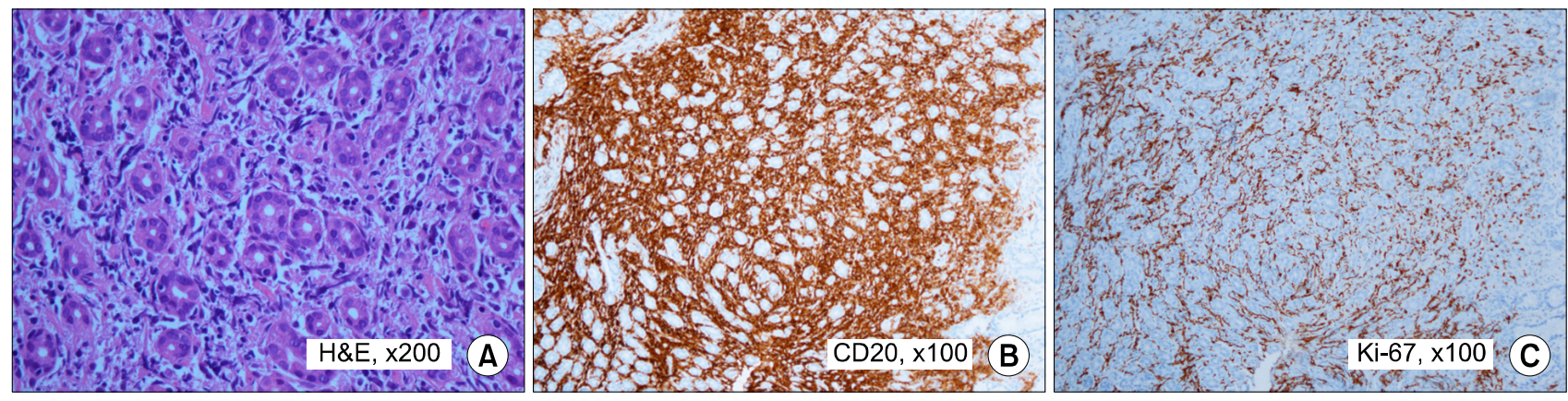

Fig. 3. (A) The second endoscopic biopsy reveals diffuse infiltration of atypical large lymphoid cells (H\&E, $\times 200)$. (B) On immunohistochemical staining, these cells are strongly positive for CD20 (CD20, ×100). (C) Tumor cells shows high Ki-67 expression $(70 \%)(\mathrm{Ki}-67, \times 100)$.

Answer: The first endoscopic biopsy from the ulcerative lesion and the thickened folds revealed only chronic gastritis. The second endoscopic biopsy from both lesions 3 days later revealed diffuse infiltration of atypical large lymphoid cells on H\&E staining (Fig. 3A). On immunohistochemical staining, these cells were strongly positive for CD20 (Fig. 3B) and showed high Ki-67 expression (70\%) (Fig. 3C). The findings of H\&E staining and immunohistochemical staining were compatible with diffuse large B cell lymphoma (DLBCL). Helicobacter pylori was not detected on rapid urease test and biopsy. Finally, we diagnosed the patient with DLBCL.

Gastric lymphoma is one of the most common types of gastrointestinal (GI) tract non-Hodgkin's lymphoma (NHL), representing $50 \%$ of all GI tract $\mathrm{NHL}$ and $3 \sim 5 \%$ of gastric malignancies. ${ }^{1}$ The clinical manifestations of gastric lymphoma is obscure and it is difficult to distinguish from other benign or malignant gastric tumors. Endoscopic findings of gastric lymphoma are various and non-specific, may range from simple mucosal changes to a resemblance to adenocarcinoma, causing a misdiagnosis. ${ }^{1}$ Several types of ulcers such as small or penetrating ulcers may be indistinguishable from benign and carcinomatous ulcers. Furthermore, the infiltrative pattern may also be observed in benign conditions such as Menetrier's disease and linitis plastica. ${ }^{2}$ In DLBCL, at the early stage of disease, the diagnostic accuracy of endoscopic biopsy is high (70 90\%), even if the efficacy can be lower in cases of deep infiltration. However, endoscopic findings alone are not adequate to distinguish the DLBCL from the ulcerative or infiltrative cancer, such as Borrmann type 4 advanced gastric cancer, and endoscopic biopsy also cannot come to the final diagnosis sometimes. In the ulcerative cancer, the cancer cells are not seen in histologic examination, and only necrosis and inflammation are reported in some cases. ${ }^{3}$ Therefore, in the case of ulcerative cancer, it is necessary to perform a biopsy at border between the ulcer and the normal mucosa, at the base of the ulcer and at the normal site. ${ }^{3}$ Of course, if cancer cells are not obtained in the first biopsy, it is better to consider more aggressive repeat biopsy. In addition to endoscopic biopsy, endoscopic ultrasonography can be useful for diagnosis of gastric lymphoma or surgical laparoscopic diagnosis also can be used as a supplementary method. ${ }^{4}$

\section{REFERENCES}

1. Cui X, Zhou T, Jiang D, et al. Clinical manifestations and endoscopic presentations of gastric lymphoma: a multicenter seven year retrospective survey. Rev Esp Enferm Dig 2017;109: 566-571.

2. Taal BG, Boot H, van Heerde P, de Jong D, Hart AA, Burgers JM. Primary non-Hodgkin lymphoma of the stomach: endoscopic pattern and prognosis in low versus high grade malignancy in relation to the MALT concept. Gut 1996;39:556-561.

3. Lee JH. Stomach cancer tissue test-strategy for negative tissue examination in cancer. Korean J Helicobacter Upper Gastrointest Res 2011;4:17-19.

4. Vetro C, Romano A, Amico I, et al. Endoscopic features of gastro-intestinal lymphomas: from diagnosis to follow-up. World J Gastroenterol 2014;20:12993-13005. 